\title{
PROBLEMS OF FINANCING SMEs IN GHANA: A CASE STUDY OF THE SUNYANI MUNICIPALITY
}

\author{
Kwadwo Boateng Prempeh ${ }^{1^{*}}$ \\ ${ }^{* 1}$ Sunyani Polytechnic Sunyani, Ghana, Email: baprempeh2002@yahoo.co.uk
}

*Corresponding Author: -

Email: baprempeh2002@yahoo.co.uk

\begin{abstract}
: -
Small and medium enterprises play an important role in the development of a country. The growth of SMEs is also important for the world economy which has been widely discussed in recent years. Although the problems SMEs face in accessing finance are well known, still there are some research gaps that need to be filled. The main focus of this research is to explore the nature and the characteristics of SMEs together with the financial constraints facing the SMEs. Basically, the research focuses on Sunyani Municipality as the main area of study, but it will also cover the problems of SMEs for the other parts of the world under the same main purpose of this research. The research is a case study. Moreover, the nature of data collected for this project is both quantitative and qualitative. Questionnaires and interviews are the main tools for collecting data. Relevant literature is also reviewed. The Researcher has concluded that many studies have shown most of the SMEs lack access to finance for starting, operating and expanding their businesses, therefore access to finance is always quoted as a major constraint for all SMEs and can seriously affect their ability to survive, upgrade the technology in their business, increase their capacity and even in many cases, expand their market, improve management system or increase productivity as well as profitability. The findings will assist policy makers, development agencies, SME owners and financial institutions to ascertain the appropriate strategy to improve the SMEfinancing.
\end{abstract}

Keywords: SMEs, Sunyani Municipality

\section{(c) $(\$)$}




\section{I.INTRODUCTION}

It is now increasingly recognized that the small and medium enterprises (SMEs) play an important role in income generation as well as employment creation around the globe. Small and medium-sized enterprises (SMEs) are considered to be one of the principal driving forces in economic development. They stimulate private ownership and entrepreneurial skills. They are flexible and can adapt quickly to changing market demand and supply situations. They also generate employment, help in diversifying economic activities and make a significant contribution to exports and trade.

SMEs are the core or basis for the future of developing countries as well as developed countries in creating jobs and competitiveness. As in the case of Europe, those enterprises which employ less than 250 employees, the so-called SMEs, have been the main source of employment growth within the non- financial sector in the European economy. This means that the SME in Europe represent about $99.8 \%$ of all European Union enterprises in 2003, in which the SMEs employ about two third of the workforce in Europe and generate more than a half (57.3\%) of its value added (Schmiemann, 2006).

Most of the SMEs nowadays are involved in the face of globalization especially in this 21 st century, whether they operate locally or internationally. It has become increasingly difficult over the past few years to discuss the development of SMEs without making a link to the globalization of the markets and thus of the economy. This means that globalization involves exchange of goods and services of all kinds, but most of the exchanges results from the formation of new alliances or agreements between businesses, as it may be seen in the computer industries, chemistry industries or automotive industries. Therefore, due to this globalization effect, we are now witnessing the extension of direct or indirect foreign investment, whereby the consequence of this globalization on consumer markets causes the variety of the products to increase rapidly across the world. Also due to the international competition, most of the SMEs are availing themselves by purchasing technologies in a great many countries, as well as the semi-finished products and raw materials so as to increase their productivity. The SMEs also seek new outside markets for their products in order to increase their profitability and be very innovative so as to compete in this world of globalization.

Thus, the importance of the SMEs in the market economies is worldwide. If we see the case of Asian Pacific economies, the SMEs account for about $90 \%$ of the enterprises in which they constitute the backbone of this region. Between $32 \%$ and $48 \%$ of the SMEs contribute to employment and between $60 \%$ and $80 \%$ contribute to gross domestic product (GDP) in individual Asia Pacific economies. In Switzerland and the European Economic Area (EEA), the SMEs are more than 16 million. Therefore, in this region, two third of all jobs are created by the SMEs while one third of all jobs are provided by large firms. Also, the United States economic performance has been stimulated by the SMEs which accounted for $43 \%$ of the job creation between 1990 and 1994 (UN/ECE Secretariat, 1997).

In Africa, the SME sector accounts for almost $90 \%$ of all the enterprises, which are located in both the rural and urban areas, whereby they provide more equitable distribution of income in all areas of the countries. This means that the SMEs are the main source of providing employment to the people and stimulate the development of the countries by promoting the entrepreneurship and the business skills amongst communities and strengthen the local production sector as well as the industrial base. Therefore, the SMEs in Africa have been considered to be a very important engine for obtaining national development goals, such as poverty alleviation and economic growth. For example, in South Africa, the SMEs accounting for about $46 \%$ of the total economic activities and $84 \%$ of private employment. It is also estimated that about $80 \%$ of the formal business sector and $95 \%$ of the total business sector are considered to be the SMEs (International Institute for Sustainable Development, Canada, 2004

However, in the case of Tanzania, the SMEs contribute significantly in the income generations, stimulating development growth in both rural and urban areas as well as creating employment (Ministry of Industry and Trade, Tanzania, 2002).

In Ghana, the idea that problems in financing small firms have significantly hindered the role they play in the overall macro-economic performance of the Ghanaian economy is deeply rooted since the overthrow of the regime of Dr. Nkrumah (Boapeah, 1993). Previous studies have identified a growing gap in the financial support offered to the Ghanaian SMEs. (Aryeetey, et al, 1994) reported that 33\% of the SMEs surveyed mention credit as a constraint.

\section{Literature Review}

General Views on Small Medium Enterprises (SMEs)

There are several reasons which make the firm small and make it different from other firms. The identification of these firms may be problematic, therefore in this study we shall try to understand the reasons why small firms are created and which are the small firms. There is no precise and universally accepted single definition of SMEs (Aikaeli, 2007). Different countries use various measures in defining the SMEs according to their level of development.

The commonly used measures are the total number of employees, sales turnover, size of the premises as well as the profitability of the firm. This means that each organization has their own definition of SMEs to suit their work or according to their work, which cause inconsistence from one business sector to the other. For example, the firm of 70 lawyers or accountants would be considered to be larger than the electrical goods manufacturing firm which have the same number of employees, i.e., 70 employees (Bolton Committee Report, 1971).

The definition of an SME, according to the European Union, is a company with up to 250 employees, turnover of up to 50 million Euros, or a balance sheet of up to 43 million Euros (European Commission, 2008). $99 \%$ of the companies in Sweden have less than 50 employees, thus making them SMEs (Nutek, 2008).

An enterprise is defined to be "any entity engaged in an economic activity, irrespective of its legal form". Three different categories are defined to include micro, small and medium-sized enterprises. Micro enterprises have less than 10 employees and an annual turnover below $€ 2$ million, small enterprises have less than 50 employees and an annual turnover below $€ 10$ million, and medium-sized enterprises have less than 250 employees and an annual turnover below 
$€ 50$ million (European Commission, 2005).

The following are the definitions of the small business as advanced by the number of sources such as the Bolton Committee of 1971, Department of Trade and Industry (DTI), European Commission and the Companies Act of 1985.

\section{The Bolton Committee Report (1971)}

In defining the small businesses, the Bolton Committee's Report (1971) on Small Business within the UK economy, has attempted to overcome the problem of defining the small business sector as there is no uniformly acceptable definition of small firms. Therefore, they formed a definition that had both a quantitative (statistical) and a qualitative (economic) element. The quantitative (statistical) definition was expressed in terms of size by observing the number of employees in some sectors and by the turnover in other sectors. Therefore, all quantitative or statistical definitions include reference to both the number of employees as well as the turnover. The main issue is to quantify the current size of the small firms and their contribution to the economy such as in the GDP, export, employment and innovation.

The qualitative definition of Bolton Report regarding SMEs must fulfill the following criteria:

- They have a relatively small market share within the industry.

- They are mainly managed by their owners or part owners in a personalized way and not by an organized structural management.

- They are independent with the owners or managers having control of the activities of the business, and should only be limited by outside elements in matters of financial obligation.

\section{Department of Trade and Industry (DTI)}

The Department of Trade and Industry (DTI) in UK defined the small business by using the number of employees as one of the determinants of the size of the firm and the turnover. This means that a clear description of the major characteristics of the SME comes from the Report of the Bolton Committee on Small Firms of 1971. Therefore, according to the DTI statistical definition, they still maintain the statistical definition of the Bolton Committee on small businesses (Tonge, 2001).

According to the European Commission (EC), in 1996 they adopted a single definition for SME that to be applied across all the Community proposals and programs from December1997 onwards. This definition is the same as that of the DTI (Tonge, 2001) However, for statistical purpose, the definition which was used by the DTI is as follows:

- Micro firm, 0 - 9 employees

- Small firm, 0 - 49 employees (includes micro)

- Medium firm, 50 - 249 employees

- Large firm, over 250 employees.

The Companies Act of the United Kingdom

According to the Companies Act, 1985 of the United Kingdom, section 248, at least two of the following criteria must be satisfied:

- A turnover of not more than $£ 2.8$ million

- A balance sheet total of not more that $£ 1.4$ million

- Not more than 50 employees.

And for the medium-sized company, the firm must at least satisfy two of the following criteria:

- A turnover of not more than $£ 11.2$ million

- A balance sheet total of not more than $£ 5.6$ million

- Not more than 250 employees.

\section{Characteristics and Nature of Small Firms}

The characteristics of the small firms are as follows:

- The small firms mainly focus on a small range of products or services and mainly sell their product or services on the local domestic market

- In small firms, the owner is the only person in a managerial position, thus, there is no organized structural management or board of directors

- The small firms operate their business on trust, rather than on contracts and systems

- In small firms the pressures of day-to-day management and resource constraints cause their vision and outlook to be bounded by the horizons, skills and experience of the owner or founder

- The small firms like to operate independently of other businesses and institutions or work on their own, i.e., they prefer more self-help rather than seeking advices

- The small firms face a fierce competition due to their small range of products and small market share; therefore, they tend to be simply price takers

- Small firms also do not have any preparations for the future plans

- Maximum small firms are not publicly owned companies; they are either partnership firms or privately owned companies, i.e., most of them are not quoted on a stock exchange

- Small firms have limited resources in terms of assets, manpower, as well as finance (Small and Medium Business, New Zealand, 2004) 
Different countries use different parameters to define SMEs. Some use the number of persons employed, amount of capital invested, amount of turnover or the nature of business. In Ghana, there is no clear definition of an SME as government agencies use various criteria to define SME. The main criteria used are the number of employees, the size of fixed investment, and the nature of business and the sector. Firms differ in their levels of capitalization, sales and employment. Hence definitions that employ measures of size (number of employees, turnover, profitability, net worth etc.) when applied to one sector could lead to all firms being described as small, while the same definition when applied to a different sector would lead to different results (Quartey, 2001).

\section{SMEs in Ghana}

SMEs are extremely important to the economy of any country whether developing or developed. They play a critical role in economic development, and Ghana is no exception. According to Rashid, et al, (2001), the SME sector plays significant role in its contribution to national economy in terms of the wealth created and the number of people employed. In Ghana, small and medium sized enterprises (SMEs) are defined as business that employ up to 29 workers (including micro-enterprise that employ 1-5 workers) with value of fixed assets greater than

$\$ 10,000$. Also, medium enterprises employ 29-99 workers with value of fixed assets of \$100,000 (GEPC, 2006). Most of the Ghanaian SME handicrafts exporting firms are mainly owned business with few employees and therefore, they are small enterprises.

In Ghana, available data from the Registrar General indicates that $90 \%$ of companies registered are micro, small and medium enterprises. This target group has been identified as the catalyst for the economic growth of the country as they are a major source of income and employment. Data on this group is however not readily available. The Ministry of Trade and Industry (MOTI), in 1998 estimated that the Ghanaian private sector consists of approximately 80,000 registered limited companies and 220,000 registered partnerships. Generally, this target group in Ghana is defined as: Micro enterprises employing up to 5 employees with fixed assets (excluding realty) not exceeding the value of $\$ 10,000$, Small enterprises employ between 6 and 29 employees with fixed assets of \$100,000 and medium enterprises: Employ between 30 and 99 employees with fixed assets of up to $\$ 1$ million (MOTI, 1998).

According to Mensah (2004), data from the Social Security and National Insurance Trust (SSNIT) reflects that, by size classifications, the Ghanaian private sector is highly skewed, with $90 \%$ of companies employing less than 20 persons. A typical profile of this target group is as follows:

1. They are, dominated by one person, with the owner/manager taking all major decisions. The entrepreneur possesses limited formal education; he/she has access to little of new technologies, market information, and access to credit from the banking sector is severely limited.

2. Management skills are weak, thus inhibiting the development of a strategic plan for sustainable growth.

3. This target group experiences extreme working capital volatility.

4. The lack of technical know-how and inability to acquire skills and modern technology impede growth opportunities.

Many non-financial constraints inhibit the success of such enterprises. SME owners are reluctant to be transparent or open up involvement of their businesses to outsiders. They seem to be unaware or oblivious of the obligations and responsibilities they have toward capital providers, and the need to acquire or seek support for technical services like accounting, management, marketing, strategy development and establishment of business linkages.

SMEs have not taken full advantage of Government-sponsored business support services such as the National Board for Small Scale Industries (NBSSI), which operates in the 10 regional capitals under the Ministry of Trade and Industries and the Ghana Regional Appropriate Technology and Industrial Service (GRATIS), a foundation that provides skill training and basic

working capital tools for start-ups. Policy interventions for the promotion of SMEs have generally had the following broad themes:

- Adequate support structure, transfer of appropriate technology

- Entrepreneurial training and labour skills development

- Access to sources of funds including reducing collateral requirements, and providing safeguards for the credit delivery system

- Promoting linkages between large and small industries (Mensah, 2004)

Small and medium-sized enterprises (SMEs) in Ghana perform a strategic role by accounting for the 95 per cent of the total number of business establishments (GEPC, 2008). These numbers suggest that SMEs contribute substantially to employment and income generation. While the domestic market is the main outlet for SMEs in Ghana, they make a significant contribution towards exports. Although direct exports from this sector may not be large, SMEs play an important role as indirect exporters. There are a large number of SMEs that manufacture export products or parts, with larger entrepreneurs coordinating such arrangements and handling direct exports. Agro-based products, wood, handicrafts, leather product, plants and manufactured products are examples of such arrangements involving SMEs which are sub contracted by large-scale exporters (GEPC, 2008).

In Ghana, most of the SMEs operate in the non-traditional exports (NTEs) sector. Over the years, Ghanaian NTEs have been performing very well based on the revenue accrued to the nation. Unfortunately, handicrafts, which are one of the sectors under the NTEs, did not perform well as compared to previous performance. The GEPC report said the 
performance of semi-processed/ processed and the agricultural sub-sectors grew positively by 35.53 per cent and 11.14 percent over the 2006 earnings. However, the handicraft sub-sector recorded a negative growth of 15.59 percent over 2006 earnings. This was because major buyers of Ghanaian crafts in the United States of America (USA) turned to the Far-East, especially Indonesia, India, and China for handicraft supplies.

Ghanaian SMEs have little access to finance, which hampers their emergence and eventual growth (Aryeetey, et al, 1994). Their main sources of capital are their retained earnings and informal savings and loan associations, which are unpredictable, not very secure and have little scope for risk sharing because of their sectorial focus. Access to formal finance is poor because of the high risk of default among SMEs and due to inadequate financial facilities. Asymmetric information on SME borrowers and imperfect competition in credit market restricts SMEs' access to the credit market. Andrea (1981), asserts that small and medium enterprises in Ghana constitute a greater percentage of the economy. There are, however, several constraints to the development of SME's, especially, the lack of access to resources and financial markets. Other constraints to SME development include difficulty in finding skilled labour to employ. There is also a problem of having access to modern technology. Many firms use old machinery, and have problems with finding replacement parts to purchase.

\section{The Distinctive Challenges of SME Financing}

Any potential provider of external debt or equity finance will want to monitor the company to determine whether it is acting in accord with the initial contract, to follow the progression of the firm and to have the means to oblige the user of funds to respect the interests of the provider of funds. There are numerous reasons why doing this effectively is more problematic for SMEs than for larger firms. Hence, banks are more likely to engage in credit rationing (i.e. not extending the full amount of credit demanded, even when the borrower is willing to pay higher interest) than larger companies, (Hoff and Stiglitz, 1981).

Storey (1994) asserts that, In the first place, the SME sector is characterized by wider variance of profitability and growth than larger enterprises. SMEs also exhibit greater year-to-year volatility in earnings. The survival rate of SMEs is considerably lower than that of larger firms. Thus, one analyst found that manufacturing firms with fewer than 20 employees were five times more likely to fail in a given year than larger firms.

In the case of SMEs, it is very difficult to distinguish the financial situation of the firm from that of its owners. The use of company cars and home accommodations for both private and business purposes are clear cases in point. Furthermore, estate tax and intergenerational succession are important issues in SMEs but usually unimportant for larger companies. Relations between the firm and its stakeholders are likely to reflect personal relationships to a much higher degree than in larger firms where such relationships are formalized. Whereas large firms are expected to observe recognized standards of corporate governance in which actors such as executives, auditors, and boards of directors are expected to conform to transparent norms, SMEs tend to reflect much more closely the personalities of their owners. The linkage between SMEs and financial markets is looser than in the case of larger companies. SMEs often obtain funds from informal sources and, thus, may be less linked to trends in the formal fixed- income or equity markets. SMEs often use internally generated funds or loans from family and friends in "quasi-equity form". Funds from close acquaintances may be obtained at sub-market rates while borrowing from formal markets may be at rates higher than those available to larger companies. (OECD, 2006)

There are also potential principal/agent problems. The provider of credit will seek to require the borrower to act so as to maximize the probability that the loan is repaid, while the borrower may seek higher risk/higher return solutions. Once financing is received, the entrepreneur may be motivated to undertake excessively risky projects, since all of the upside of the project belongs to the entrepreneur, while the lender prefers a less risky project that increases the probability that the loan will be repaid. This problem, which is potentially present in all lending, is more serious for smaller firms than for larger firms because of the blurring of the line between the firm and the entrepreneur, and due to information asymmetries. Asymmetric information is a more serious problem in SMEs than in larger firms. The entrepreneur has access to better information concerning the operation of the business and has considerable leeway in sharing such information with outsiders. However, the entrepreneur is also likely to have less training/experience in business than those in a larger company, although more adapted to operating in an uncertain environment. Hence, it may be difficult for the outside provider of financing to determine whether the entrepreneur is making erroneous decisions or for the outsider to understand the business adequately. In addition, the entrepreneur may have incentives to remain opaque, not only in dealings with financiers, but also with other outsiders such as regulators and tax authorities. (OECD, 2004b) Current Status of SMEs Financing

Poku, et al, (2009) states that, the Ghanaian venture capital and private equity industry has grown steadily over the past few years since its inception or creation by the government. This report therefore comes at a timely moment to assess the prospects of venture capital finance in Ghana. At some point in the growth of every emerging entrepreneurial business, the entrepreneur is faced with the need to obtain financing from outside sources. Considerable evidence suggests that venture capitalist (VC) firms are extensively involved in the monitoring and building of the young companies that they finance. There are many who believe that the single most important factor constraining the growth of the SME sector is the lack of finance. There are many factors that can be adduced for this lack of finance:

- A relatively undeveloped financial sector with low levels of intermediation

- Lack of institutional and legal structures that facilitate the management of SME lending risk

- High cost of borrowing and rigidities interest rates. 
Because of the persistent financing gap, many interventions have been launched by governments and development partners to stimulate the flow of financing to SMEs over and above what is available from exiting private sector financial institutions. Existing SME financing interventions can be classified under:

- Official Schemes

- Financing provided by financial institutions

\section{Official SME Credit Schemes}

According to Africa Project Development Facility (2003), Official schemes are schemes introduced by government, either alone, or with the support of donor agencies to increase the flow of financing to SMEs. Government has in the past attempted to implement a number of such direct lending schemes to SMEs either out of government funds or with funds contracted from donor agencies. These funds were usually managed by the Aid and Debt Management Unit of the Ministry of Finance and Economic Planning. Most of the on-lent facilities were obtained under specific programs with bilateral organizations in support of the Government of Ghana's Economic Recovery Program and Structural Adjustment Program. Examples of such schemes are:

1. Austrian Import Program (1990)

2. Japanese Non-Project Grants (1987-2000)

3. Canadian Structural Adjustment Fund and Support for Public Expenditure Reforms (SPER).

In all cases, the funds were designed to assist importers. For example, under the Austrian Import Support Program (AIP), the beneficiaries were to use the facility to procure equipment, machinery, raw materials and related services from Austria. The Export Finance Company, a quasi-public institution was made the sole administrator of the facility. The Japanese and Canadian facilities were similarly designed to support imports from the respective countries. While these schemes were not specifically targeted to SMEs, there were no restrictions with respect to minimum company size and many companies that would fit the SME definition were beneficiaries. The results of the direct lending schemes operated by government have been mixed. For example, under AIP, 20 companies of varying sizes benefited from the scheme. Beneficiaries were given six years made up of a one-year moratorium and a five-year repayment period. Since the loans were disbursed in 1990, the borrowers should have completely liquidated their loans by the end of 1996. However as at December 2001, only 1 out of 20 beneficiaries had fully paid (Mensah, 2004).

The results for the Japanese and CIDA schemes were much more encouraging from a recovery perspective because repayments were guaranteed by various financial institutions, although the Government has had to hire 18 debt collectors to recover outstanding indebtedness under both schemes. In addition to donor- supported schemes for direct lending, government has attempted at various times to operate lending schemes for SMEs. The schemes have included the following:

Business Assistance Fund: The Business Assistance Fund was operated in the 1990s to provide direct government lending to the SME sector. The program was widely seen to have been abused politically, with most of the loans going to perceived government supporters.

Ghana Investment Fund: In 2002, the Ghana investment Fund Act (Act 616) was passed to establish a fund to provide for the grant of credit facilities by designated financial institutions to companies. However, the scheme was never implemented.

Export Development and Investment Fund (EDIF): Under this scheme, companies with export programs can borrow up to $\$ 500,000$ over a five-year period at a subsidized cedi interest rate of $15 \%$. While the scheme is administered through banks, the EDI board maintains tight control, approving all the credit recommendations of the participating banks. (Mensah, 2004).

\section{Guarantee Facilities}

Section 13 of the Loans Act of 1970 (Act 335) empowers the Government of Ghana (GoG) to provide government guarantee to any external financiers who wish to advance funds to any Ghanaian organization and the terms of such facility require the provision of guarantee from the Government. Guarantee facilities are contingent liabilities of the Government. The onus for repaying the facility lies with the borrower and not the Government. The facility crystallizes and becomes liability due from GoG if the borrower is unable to honour his/her loan obligation and the Government is called upon to settle the facility as a guarantor. In that case the borrower is required to subsequently reimburse the Government for the amount involved. Although GoG in exercise of the relevant provisions in the Loans Act, has provided guarantees to a number of bilateral and multilateral organizations in the past on behalf of selected Ghanaian organizations in both the private and public sectors of the economy, no targeted SME guarantee facilities has been introduced.

Currently, the only government-supported loan guarantee scheme in operation is operated by Eximguaranty Company which is majority-owned by the Bank of Ghana. However, the company's operations are limited by the size of its guarantee fund. Although $₫ 10$ billion was voted in the 2004 budget to augment the guarantee fund, it is small relative to the needs of the SME sector.

\section{SME Financing from Financial Institutions}

The formal financial sector in Ghana comprises commercial banks (including Merchant Banks and Development Banks) which operate a network of 303 branches in the country; 115 rural and community banks, savings and loan companies and non-bank financial institutions. 
Recently, as banks and other financial institutions have sought to broaden their loan portfolio, SMEs have become an increasingly attractive customer group. Traditionally, however, financial institutions in Ghana have been cautious with lending to SME groups because of high default rates and risks associated with the sector. Few banks have therefore developed an explicit policy for SME target groups taking the particular requirements and needs into consideration, e.g. developing earmarked financial products and appropriate credit management systems. Only few banks have SME specific loan products, and many of these are donor funded. Few banking institutions have SME desks or departments. For the others, lending to micro and small businesses is simply transacted by credit officers from corporate finance departments of the bank who generally apply the same appraisal and lending principles to SMEs. None of the commercial banks have any specialized training for credit officers in proven SME lending techniques, and most credit officers do not have any prior SME specific experience (Ghana: Financial System Stability Assessment Update, 2003).

A recent Gesellschaft Für Technische Zusammenarbeit (GTZ) survey has provided insight into the lending practices of financial institutions towards micro and small-scale enterprises (MSEs):

1. Banks and other financial institutions have traditionally looked at the MSE sector with caution. As a result, there are usually no separate MSE lending policies, and loan requests are handled quite stringent. Some institutions only give cash-secured overdrafts to enterprises for a maximum of a six-month period after which the transaction can be renewed, pending revision. This type of overdraft can be secured by the borrower upon presentation of fixed deposit or treasury bills. A maximum of $95 \%$ of their value is granted, with a lien placed on them, to minimize the risk of default (GTZ, 2001).

2. Terms and conditions. MSE loans financed out of the normal business portfolio of a commercial bank are granted for 12 months or considerably less, secured by deposits or other sources with a view to categorize it as a "secured loan" under BoG conditions, and carries the upper band of interest rates.

3. Systems and procedures. Almost without exception, the financial institutions attempt to service SME clients with a package modified from their existing smaller "light" corporate clientele. As a result, there is strong emphasis on business documentation and financial reports. These are analyzed basically in the same format as corporate applications, including time consuming cash flow analyses.

4. All the analyzed institutions work towards a longer-term client-credit officer relationship, avoiding changes in dealing staff. However, selective checks in client files showed that changes in dealing officers are quite common. (GTZ, 2001)

\section{The Venture Capital Fund}

The small and medium enterprise (SME) sector constitutes in excess of $90 \%$ of Ghana's economy. The need therefore, to provide a secured source of financing for this sector cannot be over emphasized. SMEs, if properly structured and capitalized have the potential to grow and spearhead accelerated growth of this economy into the desired middleincome status. Unfortunately, since there is a dearth of long-term investment funds for SMEs (as a consequence of the banks and securities market shying away from high-risk investments in these sectors), it became imperative for the Government to set up a scheme that will provide long term funds for the investment needs of the SME sector (http://www.activityventure.com/).

The venture Capital Trust Fund (VCTF) is a scheme established by the government of Ghana through Parliamentary Act 680 passed in November 2004. The object of the Act is to establish a venture capital trust fund with the aim of providing investment capital to small and medium scale enterprises (SMEs). In addition, the Act provides for the development and promotion of venture capital financing in the country. A greater percentage of monies from the trust fund will be invested in priority sectors of the economy identified from time to time in accordance with the government's development strategy or policy (VCTF, GPC/A815/3001/11/2004).

\section{Activity Venture Finance Company (AVFC)}

In order to achieve the above objective, the Venture Capital Trust Fund Act recommended the setting up of Venture Capital Financing Companies to apply for funding from the Trust Fund and in turn provide credit and/or equity financing to SMEs. Activity Venture Finance Company (AVFC) is the first Venture Finance Company to satisfy all the conditions specified under section 16 of the Venture Capital Trust Fund Act 2004 (Act 680) to qualify for funding from the Trust Fund.

AVFC is a limited liability company incorporated under the company's code 1963 (Act 179) with the sole authorized business of assisting in the development of SMEs by making available for their use, equity and quasi-equity financing and providing them business and management expertise. Quasi -equity are funds, other than paid-up capital and retained earnings, employed in a business and which will remain in a business as permanent capital. AVFC is owned by the Agricultural Development Bank, the Ghana Commercial Bank and the Venture Capital Trust Fund and managed by Blackstar Fund Managers.

The functions of Activity Venture Finance Company The functions of AVFC include the following:

1. Provision of credit and/or equity financing to eligible SME's

2. Monitoring of activities of SME's financed by Activity Venture Finance Company with the aim of improving their profitability

3. Coordination and provision of post investment assistance to investee companies especially relating to capacity building 
4. Helping to improve standards of corporate governance, financial reporting, transparency and internal controls of investee companies

5. Assisting investee companies to develop and refine their business strategies for expansion and other strategic purpose ((http://www.activityventure.com/).

By the above functions, AVFC is actualizing the Government's vision of putting in place an effective mechanism for making low cost financing available to small and medium scale businesses to facilitate growth in productive sectors and subsequently create more jobs and generate wealth, which will ultimately go to replenish pool of funds available to be down-streamed to businesses for re-investment (http://www.activityventure.com/).

\section{The Significance of SMEs to an Economy}

The importance of SMEs within the industrialization period is understood again since 1970's. Perhaps now, SMEs are the seed from which economy in many developing countries is grown. This means that the role of the SMEs in developing the economy of a country varies from economy to economy, depending upon the political system of the country, industrial climate within the country and the material resources available (www.dbj.go.jp/english/IC/seminar/datafile/turkey/summary.pdf).

Today, governments worldwide recognize the importance of SMEs and their contribution to economic growth, social cohesion, employment and local development. SMEs account for over $95 \%$ of enterprises and $60 \%-70 \%$ of employment, and generate a large share of new jobs in OECD economies. As globalization and technological change reduce the importance of economies of scale in many activities, the potential contribution of smaller firms is enhanced.

Small and medium enterprises play an important role in the development of a country. The growth of SMEs is also important for the world economy which has been widely discussed in recent years. Although the growth of small firm is a well-known topic in theoretical research, still there are some research gaps that need to be filled. There is no single multidimensional theory which would embrace all possible approaches; most studies on SMEs' growth examine the growth factors one by one (Wasilczuk, 2000). There exists no single theory that can adequately explain small business growth due to the heterogeneity of SMEs. Moreover, growth itself is difficult to measure, and can be measured either objectively or subjectively (Delmar, 1996).

According to Oswald J. (2003), the importance of financial resources for SMEs is obvious: it helps to retain profits, grants, loans and equity, obtained from a range of sources including self, banks, venture capitalists, government agencies and so on. Vargas and Rangel (2007) argue that, even though the financial resources are important for a firm to leverage performance, it was found that the development of internal capabilities has been more important than limited financial resources in order to develop competitive advantages, to compete with larger and multinational competitors. It has also been argued that putting more money into start-ups is more costly than helping established SMEs to grow faster (Storey, 1994).

Small business in Africa can rarely meet the conditions set by financial institutions, which see SMEs as a risk, because of poor guarantees and lack of information about their ability repay loans (Boon, 1989). The financial system in Ghana is under-developed however and so provides few financial instruments (Aryeetey, et al, 1994). They argued that, the Ghanaian capital markets are in their infancy, shareholding is rare and no long-term financing is available for SMEs. Non-bank financial intermediaries, such as micro credit institutions, could be a big help in lending money to the smallest SMEs but they do not have resources to follow up their customers when they expand (Lassort and Clavier, 1989).

Based on the above, we start with the cautionary note that access to financing should be seen as only one component of a national SME policy. Without a holistic approach covering the key developmental constraints of SMEs, SME financing schemes implemented in isolation are unlikely to be effective.

\section{Issues in SME Financing}

Some of the reasons why SMEs face difficulties in accessing finance from external sources are as follows:

- Informational asymmetries between small businesses and lenders, or outside investors;

- The higher risk associated with small scale activities;

- The existence of sizeable transactions costs inhandling SME financing.

- Lack of collateral that typically characterizes SME

Informational asymmetries are always present in enterprise financing transactions. Entrepreneurs typically possess privileged information on their businesses that cannot be easily accessed or cannot be accessed at all by prospective lenders or outside investors. This leads to two problems. First, the lender/investor may not be able to differentiate adequately between 'high quality' and 'low quality' companies and projects. In that case, price variables (i.e. interest rates) may not work well as a screening device, because high interests may lead to an excessively risky portfolio (the 'adverse selection' problem). Second, once the lenders/investors have supplied the funding, they may not be able to assess whether the enterprise is utilizing the funds in an appropriate way (the 'moral hazard' problem). To mitigate these problems, bankers and outside investors may adopt precautionary measures, such as requiring that financing be collateralized. Ultimately, they may simply turn down the request for financing Informational asymmetries tend to pose more severe problems for SME, than for larger business. The information that SME can realistically provide to external 
financiers (in the form of financial accounts, business plans, feasibility studies, etc.) often lacks detail and rigor. This problem is often aggravated by the low level of education of small entrepreneurs, who may not be in the position to adequately articulate their case. This problem is particularly acute in developing countries. The information supplied to bankers and outside investors by family-owned SME is often not fully accurate and realistic, and opaque behavior may prevail. Under these conditions, outside financiers tend to adopt a very cautious attitude towards SME, and either reduce the amount of financing sought or refuse it altogether. (http://econ.worldbank.org/).

Another approach ascribes the difficulties faced by SME in accessing finance to their higher risk profile. Suppliers of external funds regard SME as riskier enterprises for a number of reasons. First, SME face a more uncertain competitive environment than larger companies they experience more variable rates of return and higher rates of failure. Second, SME are comparatively less equipped in terms of both human and capital resources to withstand economic adversities. Third, there is the problem of inadequate accounting systems, which undermines the accessibility and reliability of information concerning profitability and repayment capacity. In developing countries, there is the added problem of a more volatile operating environment, which has a negative impact on the security of transactions. There is a greater risk that lenders/investors will not get paid, or that assets will not be properly registered (http://econ.worldbank.org/).

Irrespective of risk profile considerations, the handling of SME financing is an expensive business. The cost of appraising a loan application or of conducting a due diligence exercise in view of a possible equity investment is largely independent from the size of the financing under consideration. For all practical purposes, the following costs are fixed: administrative costs; legal fees; and costs related to the acquisition of information, such as the purchase of a credit profile from a specialized agency. In the case of smaller loans or investments, it is more difficult to recoup these costs. Similar considerations apply to the costs that outside financiers must incur after disbursement, when conducting field inspections, or attending board meetings. Again, the problem is more severe in developing countries for the following reasons: the lack of adequate management information systems in financial institutions, the undeveloped state of the economic information industry, and the poor state of certain public services, such as the registration of property titles and collaterals. To some extent, the problem can be solved by raising the cost of financing through a higher interest rate or closing fee. This is indeed the approach adopted by many micro lending schemes, but it is possible only up to a certain point (http://econ.worldbank.org/).

According to (http://econ.worldbank.org/ accessed on 13/01/2015), in the case of debt financing, lenders typically request collateral in order to mitigate the risks associated with the 'moral hazard'. The lack of collateral is probably the most widely cited obstacle encountered by SME in accessing finance. The amount of collateral required in relation to the loan size is a measure frequently adopted to empirically assess the severity of the financing gap. In some cases, the enterprise may be unable to provide sufficient collateral because it is too new because it is not firmly enough established. That problem is closely related to the 'higher risk' argument presented above. In some cases, the lender may deem the collateral insufficient in view of the size of the loan requested. In other words, the proposed expansion project may be too large in comparison with the current size of the firm. Again, this is an issue related to the 'higher risk' argument presented above. In other cases, the collateral may be insufficient simply because the managers-owners tend to siphon off resources from the company for personal or other purposes. Again, this is closely related to the risk profile and the moral hazard issues. Lack of collateral can be viewed more as a symptom than as a direct cause of the difficult relations between SME and providers of finance. Whatever the sequence of causes and effects, it is widely acknowledged that in developing countries the issue of collateral is comparatively much more severe. The following section examines how the undeveloped state of institutional and legal frameworks, prevents the possibility of pledging the owned assets as collaterals.

\section{METHODOLOGY}

\section{Study Area}

The study was conducted in the Sunyani Municipality. The Sunyani Municipality was chosen as the research location because of its proximity to the researcher, this is because the researcher lives in the area and most of the research was conducted when the researcher was on vacation. Secondly, the research has been conducted in several locations in the country but much has not been done about the Sunyani Municipality. The Sunyani Municipality is located in the heart of Brong Ahafo Region, between Latitudes $7055^{\prime} \mathrm{N}$ and $7035^{\prime} \mathrm{N}$ and Longitudes $20 \mathrm{~W}$ and $2030^{\prime} \mathrm{W}$. It shares boundaries with the Wenchi District to the north, Berekum and Dormaa districts to the West, Asutifi District to the South and Tano South District to the East. It has a total land area of 2488 square kilometers. According to the 2005 population estimates, 80,245 people reside in the city of Sunyani, with a growth rate, in the city, of $3.4 \%$ per annum. The economy is predominantly agrarian with approximately $48 \%$ of the population engaged in agriculture production. Main crops grown are maize, yam, cassava, cocoyam, plantain, cocoa, oil palm, beans and vegetables. About 24 percent of the population is employed in the service sector, followed by commerce and industry which employ $15 \%$ and $13 \%$ of the populace, respectively. They engage in activities like the sale of clothing, grocery and building materials.

Sunyani District has a growth rate of three-point seven six percent $(3.76 \%)$. The population aged zero to fourteen constitutes 35.1 percent of the total population. The gender split is 48.5 percent for males and 51.5 percent for females. The dependency ratio is 1:1.8; average household size is 6.3 percent. Ethnicity is fairly homogenous. The Akan population is 85.4 percent of the total population. Mean annual per capita income was $\phi 170,967$ and mean annual per capita expenditure was $\notin 215,256$ as at 1996 . More so, 34.1 percent and 15.7 percent constitute the population below the 
poverty line and the hard-core poverty line respectively. There are four hundred and three (403) registered enterprises in the Sunyani Municipality as at January 24, 2010.

\section{Research Design}

This study is both descriptive and exploratory since it seeks to find out what is happening, seek insights and ask questions about problems of financing SMEs in Ghana. The study also seeks to describe events, situations and draw conclusions on data collected. The research design used to obtain the data was a survey. A survey is a research strategy that involves the structured collection of data from a sizeable population. Although the term survey is often used to describe the collection of data using questionnaires, it includes other techniques such as structured observation and structured interviews (Saunders, et al, 2007). This was chosen after a careful study and an in-depth review of related literature as to how to research into an area where both quantitative and qualitative analysis was to be made to get the right representation of the results.

\section{Population}

The population of the research consisted of all the four hundred and three (403) registered enterprises in the Sunyani Municipality as at January 24, 2010. Data on SMEs situated in the Sunyani Municipality was collected from the NBSSI office, Sunyani branch.

\section{Sampling Methods}

It is not possible to collect and gain data from all available sources to solve the research problems and to find solutions. Thus, sampling techniques provide methods that help to reduce the amount of data needed to be collected by considering only data a sub-group rather than all possible cases or elements (Saunders, et al, 2000). There are number of ways to choose a sample for case studies.

Regarding the purpose of this research the purposive and convenience sampling technique would be used. Purposive sampling enables researchers to use their judgments to select cases that will enable them to answer research questions and to meet their objectives. This form of sampling is often used when working with small samples such as in case study research when the researcher wishes to select cases that are particularly informative. Convenience sampling is a nonprobability sampling procedure in which cases are selected haphazardly on the basis that they are easiest to obtain.

Again, for this study, purposive sampling would be used since the organizations to be selected must be small medium enterprises (SMEs) situated in the Sunyani Municipality of the Brong Ahafo Region, this would best enable us answer the research questions and meet the objectives of the study. The study was delimited to selected SMEs in the Sunyani Municipality since the researcher cannot see to all companies in the country due to time and financial constraints. The following criteria will be used to select the sample:

- Registered Small Medium Enterprise

- Based in the Sunyani Municipality

The researcher then grouped the SMEs and categorized them according to their involvement in SME activities. These activities include agriculture, agro processing, manufacturing, service providers and trading and arts and artisans.

\section{Sample size}

In all, a sample of 120 businesses was selected based on their availability, willingness to participate, time and financial constraints. The sample was selected in accordance with the established objectives of the study.

\section{Instruments of Data Collection}

Research includes collection of data and analysis of data. There are three strategies for researchers to collect data for case studies: interviewing, observing, and analyzing documents. When in-depth information is required, interviews are the preferred means of data collection. Denscombe (2000) maintains that there are four main methods for collecting data; these are: questionnaires, interviews, observations and documents.

\section{Questionnaire design}

The questionnaire was one of the main instruments to collect the primary data. The main purpose of it was to develop a structure of the quantitative data which will ascertain whether SMEs really face problems is accessing finance. The questionnaire was prepared in English language. The respondents were informed about the purpose of the questionnaire and were assured that the data provided was strictly for the purpose of the research and would be kept confidential.

The questionnaire included thirty-one (31) questions structured in a way to obtain information about the respondent and the SMEs; ownership structure; sources of funds, services, number of employees, their opinions and their recommendations. The questionnaire contained pool of questions, which were close- ended questions with multiple responses directing the respondent to choose an answer and open-ended questions, the type of the question the respondent had an opportunity to add his/her opinion.

\section{Data Collection}

Data was collected from the sampled population using a questionnaire. On May 17, 2010, copies of the questionnaire were delivered to respondents by hand and prior arrangements were made with the respondents. Before the respondents 
answered the items, the researcher took his time to explain the essence of the research and the meaning of the items to them. This was to ensure that the respondents actually understood the individual questions. If the items were well understood, it would enhance reliability of responses.

In order to ensure maximum return of copies of the questionnaire, the respondents were allowed time to respond as independently and frankly as possible to the items. The copies of the questionnaire were collected after three days. This was to enable the respondents to have enough time to deliberate on the issues and bring out genuine opinions without unduly delaying the programme. In all, it took the researcher two weeks to collect data from the sampled population.

The researcher briefed the respondents of the purpose of the study and also appealed to them for their cooperation. All this was done to ensure that the respondents understood the purpose of the research to enhance the reliability of the responses. In this way, the ethical implications of the research were satisfied. A few of the respondents could not read so the researcher had to translate it into the local dialect (Twi) for them to be able to express their opinions and give their answers.

Out of the 120 questionnaires issued by the researcher, he was able to recover only a hundred (100) which he used for the data analysis. Therefore, the researcher did not get a hundred percent response rate but rather had an eighty three percent $(83 \%)$ response rate. The researcher did not get a $100 \%$ response rate because he met the absence of the respondents every time, he went there to collect the questionnaire and some of them were giving excuses.

Total response rate $=$ total number of responses/ (total number in sample-ineligible).

Yin stated three principles for data collection within a case study, in order to conduct it in a valid and reliable way. Firstly, multiple sources of evidence are to be taken into account. This relates to the concept of triangulation, i.e. increasing the overall trustworthiness of the case study by analyzing different sources of information.

\section{Quality of Research}

Researching requires the presentation of valid and reliable data. Yin (2003) suggested four tests in order to assess the quality of research: construct validity, internal validity, external validity, and reliability. In order to enhance the trustworthiness of the conducted case study, the concepts are discussed below in a critical manner.

\section{Validity}

Construct validity is concerned establishing correct operational measures for the concepts being studied. The construct validity is a critical parameter especially for case studies, because the gathered data is by nature subjectively interpreted by the researchers. It is the most complex type of validity; it is measuring an instrument to an overall theoretical framework which is used to determine whether the instrument confirms a series of hypotheses derived from an existing and at least partially verified theory (Silverman, 2006). In this Vein, instruments are not assessed in terms of how they relate to any criterion, rather to measures of concepts derived from a broader theory. It also refers to the extent to which measurement of questions actually measure the presence of those constructs intended to measure.

In order to counteract this threat, the researcher took various sources of evidence including both primary and secondary data into consideration, i.e. applying triangulation. However, the fact that web-pages not only from official and worldwide known organizations were included constitutes a potential source for errors. There was the challenge that respondents would be reluctant to reveal certain sensitive information this was overcome by using the right interview questions.

Merriam described internal validity to be the degree of match between the findings and the reality. Hence, a high level of internal validity leads to recommendations which are strategically important for the case companies. The fact that the concept of triangulation was applied contributes to high internal validity.

\section{Reliability}

According to Yin, a case study is reliable if it would lead to the same findings and conclusions if another researcher would conduct the study again, i.e., being replicable. Yin (2003) defined "the goal of reliability is to minimize the errors and biases in a study. The researcher counteracted low reliability with the concept of triangulation, and carefully documenting the conducted field study for minimizing the risk of misinterpretation. Moreover, the informal and trustful atmosphere during the interviews reduced the threat of errors. Due to the above-mentioned issues, the Researcher regards the case study to be reliable. If conducted by other researchers again, the same conclusions might be found.

\section{Ethical considerations}

The ethical considerations that guided this study were those presented by Rubin and Babbie (1997). They indicated that participation in research should:

- be voluntary and informed consent;

- ensure there is no harm to participants;

- be anonymous and confidential; and

- not deceive subjects.

Voluntary and informed consent: the researcher explained the purpose of the research to the respondents and solicited their consent before giving them the questionnaire.

No harm to participants: It was agreed that results of the thesis will be shared with the respondents in order for them to 
confirm that it accurately reflects the views they shared during the interview and no part of it embarrass them or injures the reputation of their firm.

Anonymous and confidential: It was agreed that the names of their enterprises would not be mentioned in the research results. This will ensure that comments are not directly attributable to individual SMEs in order to guard against confidentiality issues with the public. This also helped to remove some bias since interviewees were comfortable discussing the issues.

Deceive subjects: In order to avoid deception of identity, the researcher introduced himself before each interview and the researcher also explained the objectives of the research for them to also understand the objectives of the research before the respondents were handed the questionnaire.

\section{IV.Analysis And Discussion \\ Analysis of Questionnaire}

This section presents the results of the data obtained from the questionnaire during the survey. The responses that emerged from the questionnaire highlighted the problems/ challenges SMEs in the Sunyani Municipality face in accessing finance. The 100 questionnaires recovered from the respondents out of the total of 120 are going to be analyzed.

Table 1: Status of respondents in the business

\begin{tabular}{|c|c|c|}
\hline Position & Number of respondents & Percentage (\%) \\
\hline Owner & 73 & 75 \\
General Manager & 22 & 22 \\
Accountant & 5 & 5 \\
Other & 0 & 0 \\
Total Response & $\mathbf{1 0 0}$ & $\mathbf{1 0 0}$ \\
\hline
\end{tabular}

From Table 1, out of the hundred (100) respondents, seventy-three (73) which represented seventy three percent of the people who responded to the questionnaire were owners, twenty-two (22) of the respondents representing twenty two percent of the respondents were general managers and five (5) respondents representing five percent were accountants. Observations made by the researcher revealed that only one person mostly the owner was in-charge of the day-to-day management of the SMEs. So there exist no complex organizational structures.

\section{Chart 1: Educational Level of the Respondents}

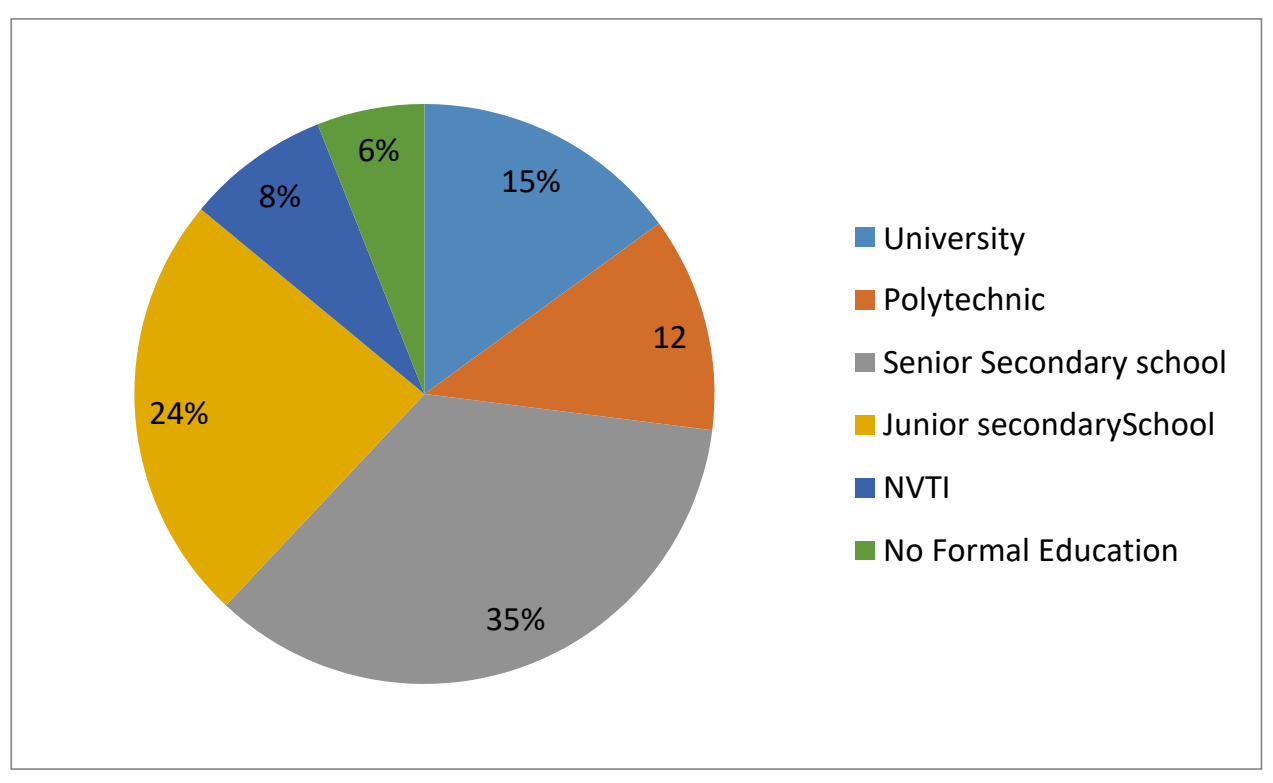

From Chart 1, on the educational background of the respondents, thirty-five (35) of the respondents representing thirty five percent $(35 \%)$ were senior secondary school (SSS) graduates, twenty-four (24) of the respondents representing twenty-four (24\%) of the respondents were junior secondary school (JSS) graduates, fifteen (15) of the respondents representing fifteen percent $(15 \%)$ of the total respondents were university graduates. Twelve (12) of the respondents were polytechnic graduates and those with other qualifications were fourteen (14), eight (8) of them were NVTI graduates and six (6) had no form of formal education. They represented eight (8\%) percent and six $(6 \%)$ percent respectively. The indication is that almost all the respondents had some form of formal education, this means that most of the respondents will or understand the study being undertaken. The study also revealed that the level of education of the respondent also affected the source of finance of the SMEs. Those with higher education tend to prefer bank loans than those with lower education. 


\section{Chart 2: Nature of Business of Respondents}

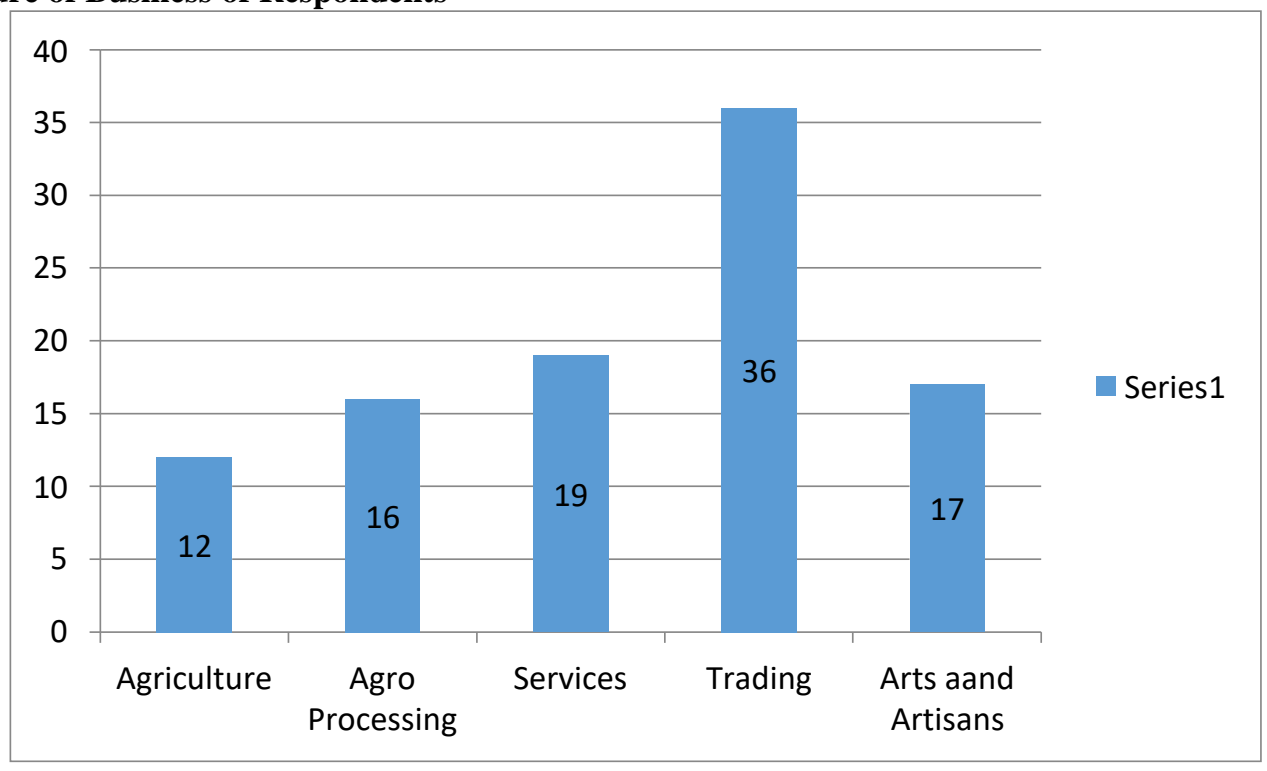

From Chart 2, Thirty six (36) of the respondents making up 36\% of the total respondents were engaged in trading (Traders), nineteen (19) of them representing 19\% were engaged in the service industry, seventeen (17) of the respondents representing $17 \%$ were artisans, sixteen (16) of the respondents, constituting $16 \%$ of the total respondents were engaged in agro processing and last but not the least, twelve (12) of the respondents were engaged in agriculture and they represented $12 \%$ of the total respondents.

\section{Chart 3: Ownership Structure of SMEs Interviewed}

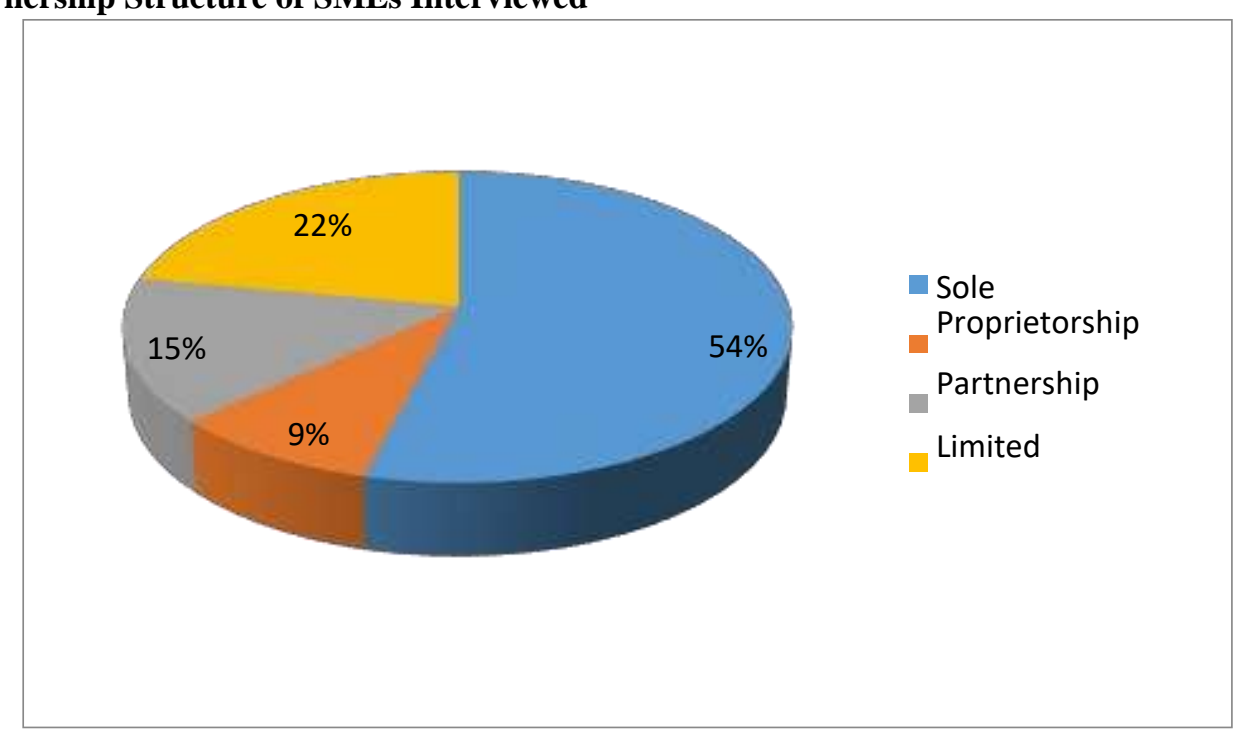

From the figure above (Chart 3), fifty-four (54) out of the hundred (100) SMEs were owned by individuals' i.e sole proprietorship. This figure represented $54 \%$ of the total response, twenty-two (22) of the SMEs were family owned representing $22 \%$ of the responses, fifteen (15) were limited liability representing $15 \%$ of the total responses and nine (9) were partnerships representing 9\%. Sole Proprietorship is owned and run by an individual and there is no legal discrimination between the owner and the business. All profits and losses accrue to the owner, the owner also has unlimited liability. The owner has full autonomy with regards to business decisions. Family-owned business may also be managed by individuals who are not family members. However, family members are often involved in the operations of their family business in some capacity and in smaller companies, usually one or more family members are often senior officers or managers. A limited liability company combines some aspect of a corporation with those of sole proprietorship or partnership. From the studies it was realized that sole proprietors found it more difficult to access finance whereas limited liability did not show that high level of difficulty. This might be as a result of low creditability of owners/ managers of sole proprietor business which lenders believe it's a high-risk business. 
Table 2: List of Employees of SMEs Interviewed

\begin{tabular}{|c|c|c|c|}
\hline $\begin{array}{c}\text { Number of } \\
\text { Employees }\end{array}$ & Number of Respondents & Percentage (\%) & Category \\
\hline $1-5$ & 68 & 68 & Micro Enterprise \\
$6-29$ & 30 & 30 & Small Enterprise \\
$30-99$ & 2 & 2 & Medium Enterprise \\
Total Response & $\mathbf{1 0 0}$ & $\mathbf{1 0 0}$ & \\
\hline
\end{tabular}

In Ghana, Small and medium enterprises (SMEs) are defined as business that employ up to 29 workers (including micro-enterprise (1-5)). Also, medium enterprises employ between 29-99 workers with fixed assets of $\$ 10,000$ and $\$ 100,000$ respectively (GEPC, 2006). From the above definition, in-terms of the number of employees, we can say that $68 \%$ of the SMEs were micro-enterprises and $30 \%$ were small enterprises, whilst the medium enterprise constituted $2 \%$. The fixed assets of the SMEs were not known so the researcher is basing his judgment using only the number of employees. The findings indicated that the number of employees was between 1 and 99 making all of them fall within the range earmarked to be accepted as SMEs.

This is the track record of the SMEs and is very important. Financial institutions and other sources of finance usually require a minimum number of years the company has been in existence before they qualify to get financial assistance (loans) from them. Twenty-eight (28) of the SMEs has been in existence for between 1- 5 years, thirty-five (35) has been in existence for between 6 -10 years, nineteen (19) of them for between 11 to 15 years, twelve (12) of them has been in existence for between 16-20 years and six (6) has been in existence for more than 20 years. This shows that most of the respondents has been in business for more than five years and understood the market they were operating in as well as the financial option available to them. When the researcher made further enquiries, he found out most of the SMEs do not keep proper records of the activities for the past years. This shows that most of them lacked proper book keeping.

The seventh item on the questionnaire was to find out the initial capital they employed, that was the money that was used to start the business. From the figure below (Fig.4), thirty (30) of the respondents employed an initial capital of less than $\mathrm{GH} \phi 1,000$, forty-eight (48) of the respondents used an initial capital between $\mathrm{GH} \phi 1,000-\mathrm{GH} \phi 5,000$, fifteen (15) of the respondents used an initial capital between $\mathrm{GH} \phi 5000-\mathrm{GH} \phi 10,000$ and seven (7) of the respondents employed an initial capital of between $\mathrm{GH} \phi 10,000-\mathrm{GH} \phi 50,000$. From the questionnaire it can be observed that those engaged in trading and agro processing employed high initial capital as compared to those engaged in services and the artisans.

\section{Chart 4: Initial Capital and Number of Responses}

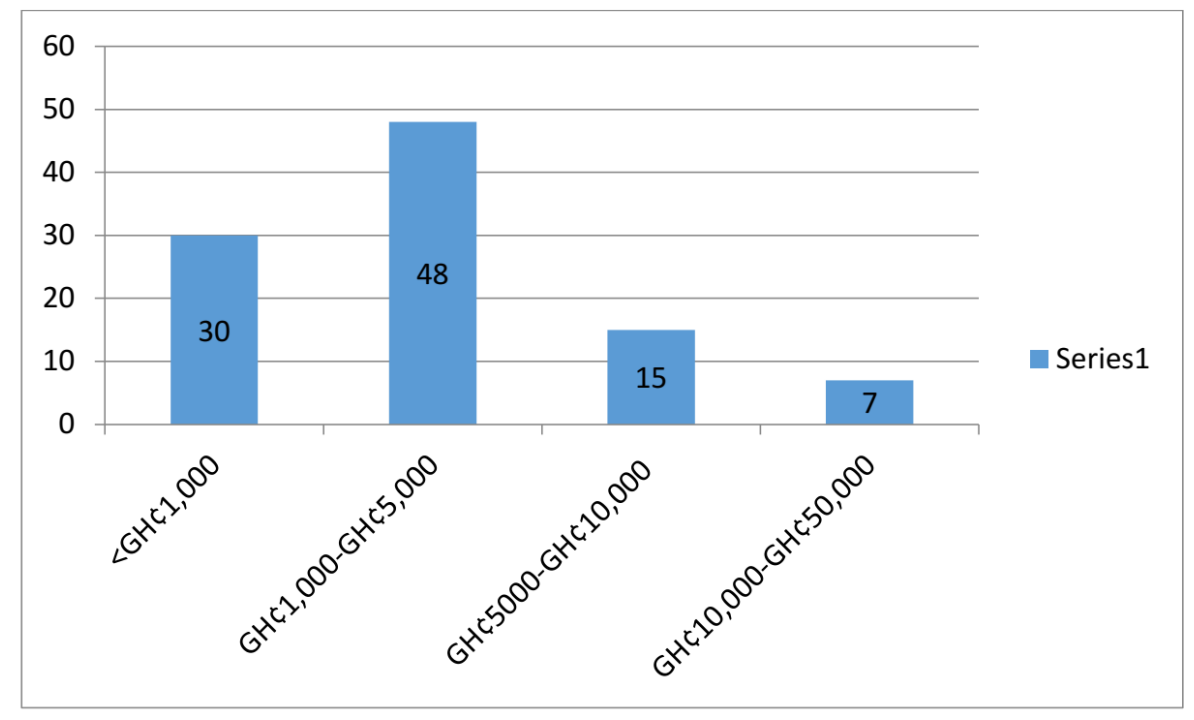

From Chart 5 below, thirty-five (35) of the respondents constituting 35\% of the respondents started their business with their personal savings, twenty-five (25) of the respondents constituting $25 \%$ of the total started with loans acquired from banks, twenty-one (21) of the respondents constituting $21 \%$ had their initial capital from credit unions, twelve (12) of the respondents started their business with contribution from the family. Last but not the least, seven (7) of the respondents started their business with the support of NGOs/Government. From this analysis the researcher can say that the major source of finance available to SMEs in the Sunyani Municipality is the personal savings, followed by loans from banks. Findings from the questionnaire also indicated that the ownership style of SMEs affected their choice financing. The study revealed that sole proprietors are likely to use personal savings than loans from bank. 
Chart 5: Source of Initial Capital for Respondents

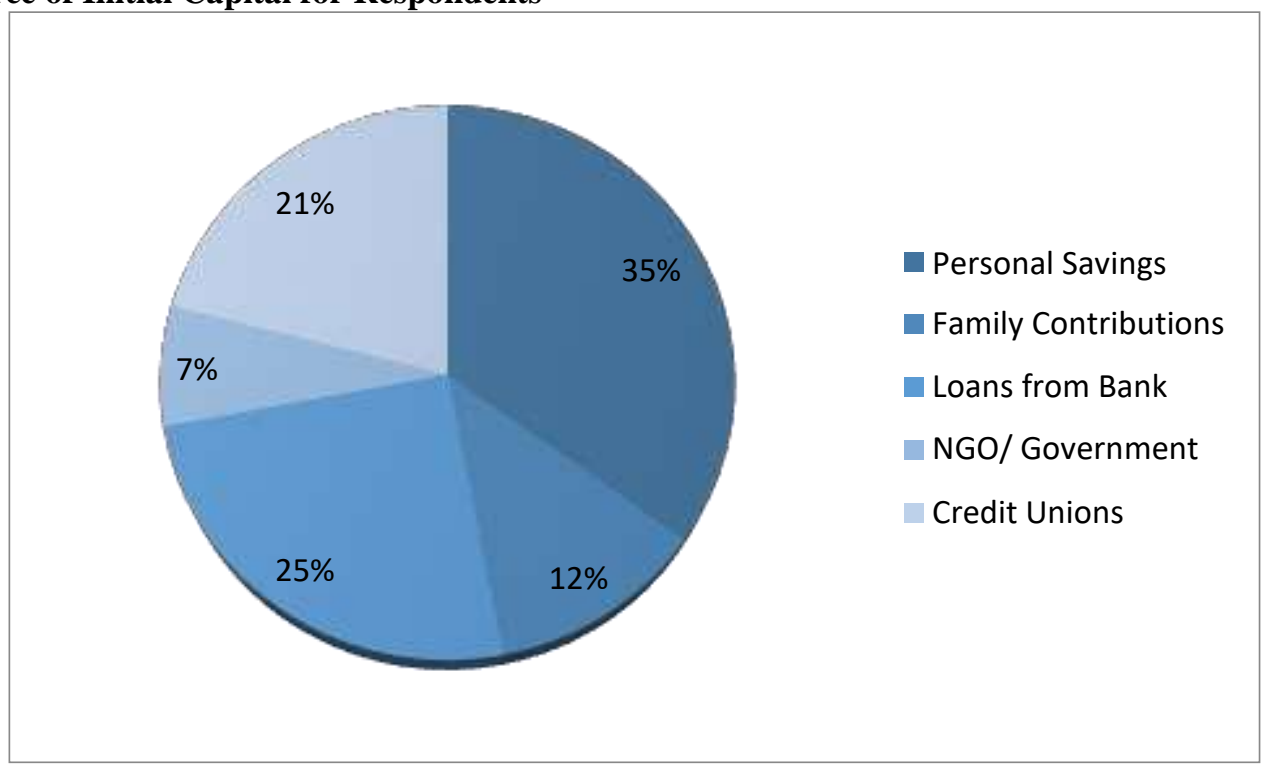

Table 3: List of Responses for Adequacy of Finance for its Purpose

\begin{tabular}{|c|c|c|}
\hline Response & Number of Respondents & Percentage (\%) \\
\hline Yes No & 22 & 22 \\
& 78 & 78 \\
\hline Total Responses & $\mathbf{1 0 0}$ & $\mathbf{1 0 0}$ \\
\hline
\end{tabular}

As to whether the finance was adequate for its purpose, seventy-eight (78) of the respondents answered "No" the number of respondents who answered no represented $78 \%$ of the respondents. Twenty-two (22) of the respondents answered "Yes", they represented $22 \%$ of the total respondents. Those who answered no also added that there were a lot of things they had wanted to do but could not due to financial constraints.

When interest rates are high people do not want to take loans from banks because it is more difficult to pay back the loans, when interest rates are low, people are likely to take loans. When interest rates are very low it may not be beneficial for lenders who are seeing less of a return of their loan than in times when interest rates are high. On this questionnaire item only the 46 respondents who took loans from the banks and credit unions as their initial capital answered. And the interest charged was between $24 \%-37 \%$. This is relatively high if compared to the interest rate in other countries.

Out of the forty-six who responded to this questionnaire item, which was to find the repayment period of the loans, eleven (11) of them answered between 1-6 months, twenty-eight (28) choose between 6-12 month and seven (5) chose between 1-2 yrs. This shows that most of the financial institutions issue short term loans, which might not be beneficial to SMEs because most of the SMEs might not be able to service the cost of finance and make enough to repay the amount loaned.

When they were asked about the impact of loans on their business, this questionnaire item generated a mix of both positive and negative responses. Some of the positive responses were; Productivity was increased, hence sales. They were able to expand their business, enter new markets and which improved the cash flow of the organization. It helped them to invest in new projects which also generated profits. Some of the negative responses were; high-cost o production, which resulted in high selling prices this reduced the total amount of sales, so it affected profits and difficulties in meeting other short-term liabilities because interest on the loan must be paid.

On their view about the performance of their enterprises, thirty seventy-nine (79) of the respondents, constituting 79\% believed that their enterprises are performing and has brighter future prospects. Twenty-one (21) of the respondents constituting $21 \%$ of the of the total respondents thinks their enterprises are not performing well. About the general performance of SMEs in the Sunyani Municipality, fifty-six (56) of the respondents were of the view that SMEs in the Sunyani Municipality are performing well and forty-four (44) of them were of the view that SMEs in Sunyani are not performing well.

When respondents who answered "No" to whether SMEs in the Sunyani Municipality are performing well, here are some of the factors they gave as contributing to the poor performance SMEs in the Sunyani Municipality:

- Low patronage of products and services by customers.

- Lack finance to expand their business and improve the quality of service and product.

- Lack of financial support from the financial institutions, government and otherstakeholders.

- High interest rate on loans and high government taxes

- Lack of proper managerial skills

- Low economic activities and people do not have enough money to spend. 
- People prefer buying from the major cities (Accra and Kumasi).

When respondents were asked to list some of the financial constraints they encounter in their line of business, here are the responses they gave:

- Lack of money for expansion projects and for research and development and employ more workers.

- Long and stringent procedures in securing loans from financial institutions.

- Lack of capital to introduce new or update existing technology.

- The resources to market their products and service well.

The respondents gave some ways of overcoming these financial constraints, some of the ways of overcoming the financial constraints are as follows:

- The process and procedures of acquisition of loans from banks by SMEs should be restructured to be less stringent.

- Financial institutions should monitor various SMEs they give loans to and provide them with technical support so that they improve upon their performance.

- SMEs should be able to manage their debtors and creditors period well.

- They should employ qualified accountants to monitor the cash flows of the organization.

On the question of whether they face difficulties in accessing funds from their source(s), seventy-seven (77) of the respondents representing $77 \%$ answered "Yes" and twenty-three (23) representing 23\% of the respondent answered "No".

Some of the difficulties which they encounter when accessing loans/ finance are:

- Provision of collateral and guarantors.

- Some of the financial institutions/ lenders are reluctant to give loans to people engaged in certain kind of businesses unless the person provides collateral.

- Delays in the processing of the loan forms.

- High interest rate charged by the financial institutions makes it difficult to service the loans, this scares a lot of people off.

- Some of the financial institutions will like you to save with them for a period of time before you are able to apply for a loan.

- The government loans do not find its way to the right people.

On the question of whether the money was used for a different purpose apart from what it was intended for, eighty-two (82) of the respondents making up $82 \%$ of the total respondents answered "No" and eighteen (18) of them constituting $18 \%$ of the total respondents answered "Yes". They did not indicate what they used it for, whether personal or other business duties. Most of the time when a loan is used for another purpose other apart from what it was intended for it leads to default. In general, the responses obtained indicated that majority of the SMEs are committed in the growth and progress of their business.

This questionnaire item was to find out whether financial institutions or their source(s) of finance demanded collateral before financing was giving to them, eighty-four (84) of the respondents representing $84 \%$ of the respondents answered in the affirmative and sixteen (16) representing $16 \%$ of the respondents answered "No". It can be said that most of these SMEs do not have ways and means of providing collateral in order to secure a loan. This has made it very difficult for most of the SMEs to access finance from financial institutions.

On the issue of whether they support the assertion that collateral should be provided before financing is giving to SMEs, seventy-four (74) of the respondents representing 74\% of the total respondents answered "No" and twenty-six (26) of the respondents representing $26 \%$ of the respondents answered "Yes". Some of the reasons those who answered yes are:

- It makes sure that SME owners do not misuse or misapply the loan/finance, if they have in mind that they will lose something valuable if they default in the payment of the loan.

- It serves as a security for the one issuing the loan, so that the one issuing the loan do not lose if the loan recipient default or refuses to pay.

Some of the reasons given by those who answered no were:

- Not all SMEs have the relevant collateral that will enable them to gain access to loans from the various financial institutions. Rather, the financial institutions should develop a mechanism to ensure that the finance/ loan is being used for the right purpose which will improve the cash flow of the SMEs so that they are able to repay borrowed amounts.

From chart 6 below, sixty two (62) of the respondents were of the view that they were able to access the finance needed because they were able to provide the necessary collateral. Two (2) of the respondents were of the view that they were access the finance because of their personal experience in the business. Nine (9) of the respondents were of the view that they were able to access the finance due to the nature of business they are engaged in, three (13) of the respondents were of the view the facility was granted because of their available stock or personal capital, eight of the respondents were of the view that it was due to their credit worthiness and six (6) of the respondent were of the view that they were 
granted the facility because of the number of years they have been in business. From this analysis, it can be seen that $62 \%$ of the respondents obtained the facility because they were able to provide the necessary collateral, $2 \%$ were able to obtain the facility because of their personal experience, $9 \%$ because of the nature of business they are engaged in, $13 \%$ were able to obtain the loan/finance because of their stock available or the personal capital employed and $8 \%$ because of their credit worthiness and they have been saving with the financial institution for a period of time and $6 \%$ because of the nature of years they have been in business.

Respondents were asked to list how the issue of collateral is affecting their sourcing of funds, and some of the responses they gave were;

- Due to the issue of collateral sometimes they are not able to obtain sufficient funds because the collateral may not be adequate or sufficient to secure them the amount they had wanted.

- Because they were not able to provide collateral their loans were not granted. The amount to be given depends on the collateral provided.

On the issue of whether they were able to pay on time $38 \%$ of the respondents answered "No" and $62 \%$ of the respondents answered "Yes". Therefore, 62 of the respondents were able to pay their loan on time and 38 of them defaulted.

Some of the reasons that led to the default as given by the respondents are, the money was not given to them on time, the money was given to them at a later date and the money given to them was not adequate for the intended purpose and last but not the least, the money was not used for the intended project. A few also attributed it to poor sales.

Among those who defaulted, sixteen (16) of them said they were threatened with legal action and twenty two (22) said they were able to plead with the financial for the duration to be extended and terms of the loan renegotiated at an additional cost to the SMEs.

\section{Chart 6: Frequency of factors that contributed to the finance being granted}

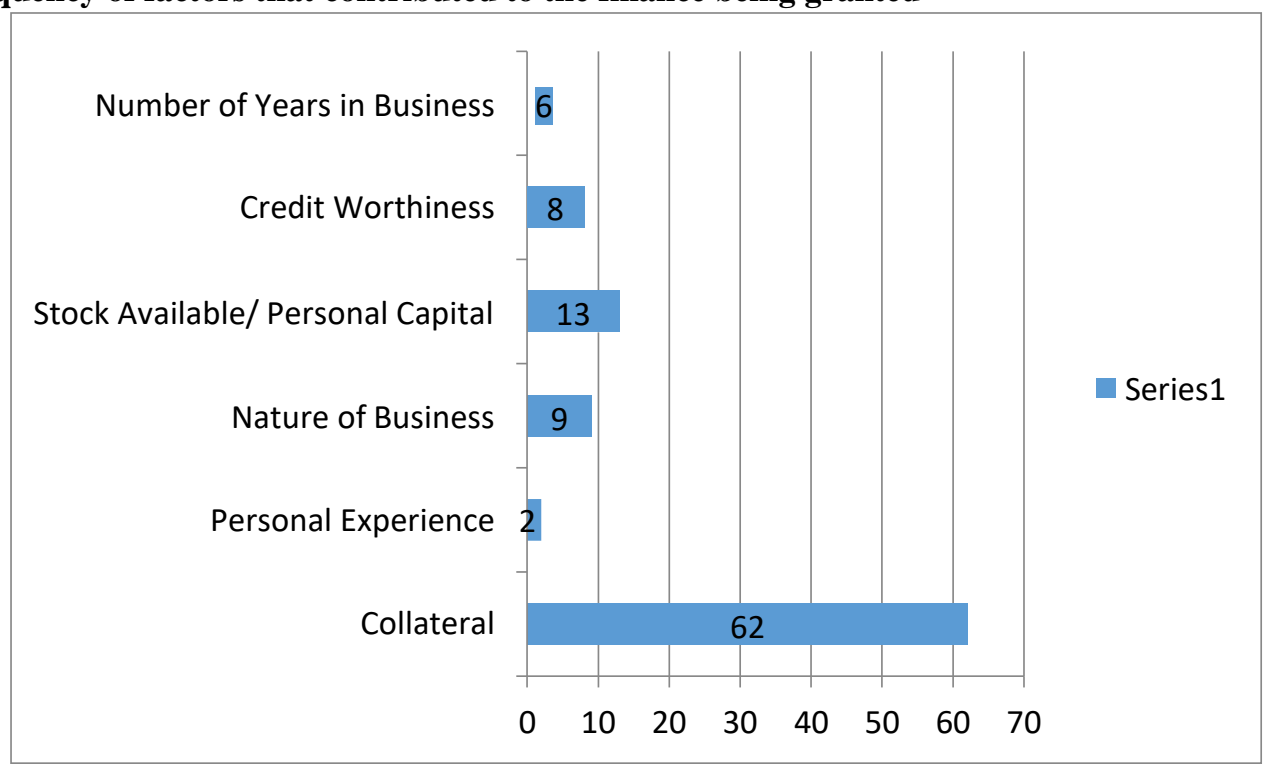

The responses the respondents gave on what can be done in order to improve SME financing in the Sunyani Municipality are;

- Non-Governmental Organizations (NGO) should come to the aid of SMEs by providing technical assistance and financial support.

- Government should set up a special fund to the well development of SMEs. By providing an interest free or low interest rate loans and grants to promote the establishment and development SMEs.

- Government should reduce the tax burden on SMEs by giving them some tax exemptions.

- Financial institutions should be less stringent on the provision of collateral by SMEs before a facility is granted and they should reduce the time they use in processing the loan application.

The last item on the questionnaire was to find out the views of the respondents on how SMEs can finance their business. Here are some of the responses;

- SMEs should plough back their profit or re-invest their profits in the business.

- Owners of SMEs should avoid misapplication of funds.

- SMEs should always seek financial advice from experts or people with experience to help them make better financial decisions.

- They should develop the habit of proper book keeping and keep records of their activities.

- SMEs should develop the habit of saving. 


\section{Conclusion}

A vibrant SME sector is considered as one of the principal driving forces in the development of a country. They stimulate private ownership and entrepreneurial skills, and are flexible and can adapt quickly to changing market demand and supply situations, generate employment, help diversify economic activity, and make a significant contribution to exports and trade. Even in the developed economies SMEs account for a large share in productivity and employment.

There are many constraints in developing the SME sector in Ghana. Several studies have identified different constraints, ranging from access to finance to marketing their products and services. However, access to finance is considered as the main constraint. Financial institutions are found reluctant to extend credit to the SME sector. The main reasons are:

- Poorly compiled records and accounts, especially audited accounts (lack of proper book keeping)

- Low level of technical and management skills

- Outdated technologies with few economies of scale and unacceptable rates of return

- Lack of collateral

- SMEs' limited knowledge of business opportunities

Finance plays a central role in enterprise development but this is only possible if it is accessible and reasonably priced. Where SMEs succeed in accessing financial resources, the cost of funds (interest rates) is high, sometimes leading to non-performing loans. Therefore, while finance, would play a crucial role to enhance enterprise development, both the countries within which SMEs are located and SMEs themselves need to overcome constraints that would impede their access to financial resources. Countries such as Ghana, therefore, should create the necessary policy, legal, and regulatory environment. This should be supported by the establishment of effective information dissemination systems such as credit reference bureaux to provide information on the credit history of borrowers.

Many studies have shown that most of the SMEs lack access to finance for starting, operating and expanding their businesses, therefore access to finance is always quoted as a major constraint for all SMEs and can seriously affect their ability to survive, upgrade the technology in their business, increase their capacity and even in many cases, expand their market, improve management system or increase productivity as well as profitability. The study has shown that most of the SMEs suffer from inadequate control and poor planning. This means that the SMEs did not have any long-term business plans and they were just focusing on the near future. Also the majority of the people enter into the business due to lack of adequate education and difficulty of finding employment from the public sectors or a formal employment. This implies that SMEs are seemed to be the last resort to the majority due to the above reasons. The study also shows that most of the financial institutions' policies and lending requirements are not SME friendly in a way that would facilitate SMEs in obtaining finance easily and sufficiently.

\section{Recommendations}

The purpose of this study was to find the problems and challenges SMEs encounter in accessing finance and ways in which SMEs will be able to access finance easily and sufficiently. Therefore, several important recommendations emerge from this study. First of all, improving their business conditions, this means that proper financial records should be kept and clear accounting standards should be adopted by the SMEs.

There is the need to educate SMEs about banking methodologies for granting loans. This would clear the myths and beliefs held about the banking system. SME's need to be properly organized to make them able to access loans from banks. Most SME's have not been able to access loans because over the years they have not built up the right information, e.g., book keeping and accounts to enable proper assessment to be done by the banks.

Financial institutions tend to charge SMEs higher interest rates and adopt a rigorous and pre-emptive approach with respect to collateral because of the difficulty they face in identifying creditworthy and promising SMEs. The most efficient way to encourage lending to SMEs is to improve the ability of existing institutions to construct profitable and efficient lending programmes. This can be achieved by minimizing the risks through appropriate tools and methodologies that assess the credit worthiness of potential SME borrowers and lower the overall costs of lending to them.

Capacity building efforts also need to be extended to the SMEs. In many cases, they are not aware of the different financial options available to them and fail to seek financing in the first place. Their skills are often limited in preparing the financial information and business plans that bank require making lending decisions. In addition, management skills required to run an expanding business successfully need to be improved. In this instance, business development service providers, with the support of the stakeholders, can play a pivotal role in improving the credit worthiness of SMEs. The most relevant way to build capacity among SME entrepreneurs could be reaching out through posters and pamphlets developed in local languages. The financial institutions could also take the lead in organizing certain "financing fairs" for SMEs in order to address some of the critical aspects involved. The financial institutions could also employ relationship managers to reach out to prospective SME clients and provide services at their doorsteps in order to understand each other better and facilitate services adapted to their needs.

The government should pay attention on improving financial literacy of entrepreneurs and individuals. The capacity of individuals and entrepreneurs to take advantage of available financial services (and to avoid risks) depends to some degree on adequate financial education. It Help SMEs to better understand the financing options available including existing government programmes and become better prepared to take on an investment. There is some evidence that SMEs fail to utilize existing programmes suggesting that they suffer from the general lack of information on the part of 
SME management.

A major reason for SMEs being overlooked by banks is that they are perceived as high-risk, the use of credit guarantee is also another important recommendation in improving the business condition of the SME. The Government should encourage the formation of small business associations that can provide an insurance (or guarantee) on loans to their members. These associations would be able to spread out risks associated with SME loans through a large number of its members.

Governments need to ensure that the requirements for the existence of a viable equity market are in place. These requirements include: an adequate supply of well-trained fund managers who can properly access the risk profile of innovative SMEs; a viable exit mechanism such as secondary stock markets where investors have potential to reap high rates of return on their investments; investment regulations that are flexible enough to allow institutional investors to participate in the equity financing of innovative SMEs. For transitional and less developed countries, creating an efficient and liquid equity market takes time. In this case, innovative SMEs need to result to government programmes, bank loans or foreign equity markets for financing.

To sum it all:

Financial institutions need to:

- Understand the dynamics of SMEs

- Design new approaches for reaching out to SMEs

- Design appropriate products for SMEs

- Provide appropriate training to their staff to respond to those needs

SMEs need to:

- Understand what borrowing from a bank is all about

- Present themselves as viable businesses

- Prepare credible project proposals

- Keep financial accounts

The Government need to:

- Create an enabling policy, legal and regulatory environment

- Facilitate development of various financial markets

- Address issues of market failure through capacity building of SMEs

- Create a framework for providing public information

Donors need to:

- Support the Government, SMEs and microfinance institutions in a coherent and coordinated manner

\section{References}

[1].Africa Project Development Facility (2003), Loan Products Summary for Ghanaian Banks and Financial Institutions, APDF, Accra.

[2].Aikaeli, J. (2007), "Improving Competitiveness for SMEs to Harness Available Trade and Investment Opportunities: The Case of Tanzania." Monetary and Financial Affairs, Bank of Tanzania. A Paper Presented in the International Conference on SMEs and International Trade.

[3].Andrea, G. (1981), Industry in Ghana, Scandinavian Institute of African Studies, Stockholm.

[4].Andersson, L. and Svensson, L. (1999), "World Wide Web Impact on marketing activities of Small Firms", Master's thesis, Lulea University of Technology, Lulea

[5].Aryeteey, E. and Fosu, F. (2006), Economic Growth in Ghana (1960-2000), available at: www.wcfia_havard.edu.conference/batesafrica/PaperPDF/AryeeteyGhana.pdf (assessed on 1st May, 2009).

[6].Aryeetey, E.A., Baah Nuakoh, Duggleby T., Hettige H. and Steel W.F. (1994), "Supply and Demand for Finance of Small Enterprises in Ghana", World Bank Discussion Papers, No.251, African Technical Series, Washington D.C.

[7].Boapeah, S.N. (1993), "Developing Small Scale Industries in Rural Regions: Business Behaviour and Appropriate Promotion Strategies with reference to Ahanta West District of Ghana", Dortmund

[8].Bolton Committee Report. 1971. "What is a Small Business." http://www.lamp.ac.uk/mit/pdf/report1.pdf (assessed on 1st May, 2009).

[9].Bryman, A., \& Bell, E. (2007), Business Research Methods Oxford: Oxford University Press.

[10]. Delmar, F. (1996), Measuring Growth: Methodological Considerations and Empirical Results, Paper presented at the RENT X Conference, Brussels, Belgium, November.

[11]. Dencombe, M (2000), The Good Research Guide: for Small Scale Social research projects. Open University press. Buckingham Philadelphia.

[12]. European Commission (2005), "The new SME definition. Enterprise and industry publications"

[13]. Fisher, C. (2004), Researching and Writing a Dissertation for Business Students, Prentice-Hall.

[14]. "Financing of SMEs in Turkey." http://www.dbj.go.jp/english/IC/service/seminar/datafile/turkey/summary.pdf

[15]. Gesellschaft Für Technische Zusammenarbeit (GTZ), "Promotion of Small and Micro Enterprises Financial Sector Market Study", Republic Of Ghana Final Report, 08. September 2001

[16]. Ghana: Financial System Stability Assessment Update, December 2003, IMF Country Report No. 03/396 
[17]. Guba, E.G. and Lincoln, Y.S. (1994) ," Paradigmatic Controversies, Contradictions and Emerging Confluence”, Handbook of Qualitative Research (1st edn): By Denzin and Lincoln, SAGE Publication Inc, pp106

[18]. Hoff, K, and J.E. Stiglitz (1981), "Imperfect Information and Rural Credit Markets-Puzzles and Policy Perspectives", World Bank Economic Review4: 235-250.

[19]. International Institute for Sustainable Development, Canada. 2004. "Issue Briefing Note: Small and Medium-sized Enterprises."

[20]. http://inni.pacinst.org/inni/corporate_social_responsibility/standards_sme.pdf (assessed on 21st April, 2008). Issues on SME Financing

[21]. http://econ.worldbank.org/ accessed on 13/09/2009)

[22]. Leavy, B. (1994), "The Craft of Case-based Qualitative Research"; Irish Business and Administrative Research, Vol. 15, pp.105-18.

[23]. Mensah, S.(2004), “A Review of SME Financing Schemes in Ghana”, Presented at the UNIDO Regional Workshop of Financing Small and Medium Scale Enterprises, Accra, Ghana, 15-16 March 2004

[24]. Merriam, S.B. (1998), Qualitative Research and Case Study Applications in Education, Jossey Bass.

[25]. Nutek. (2008) 100000 syss elsatta i miljöföretag. http://www.nutek.se/sb/d/198/a/3498 (assessed on 21st December, 2009)

[26]. OECD (2006), The SME Financing Gap: Theory and Evidence, vol.1, Paris OECD

[27]. OECD (2004b), Financing Innovative SMEs in a Global Economy, Background Report for the 2nd OECD Conference of Ministers Responsible for SMEs, Istanbul, Turkey, 3-5 June, 2004.

[28]. Oswald J. (2003), "Competitive advantage in SMEs: Towards a conceptual framework. Competitive Advantage in SMEs”, Organizing for Innovation and Change, Manchester Metropolitan University.

[29]. Poku K., Frimpong A. F., (2009), "The Assessment of the Prospects of Venture Capital Finance in Ghana": The Views and Perception of Some Selected SMEs in Ghana, Ninth Annual IBER \& TLC Conference Proceedings.

[30]. Quartey P. (2001), "Regulation competition and Small and Medium enterprises in Developing Countries", IDPM Working Papers, University of Manchester, No.10

[31]. Rashid, M.A. and Al-Qirim, N. A (2001), E-commerce technology adoption framework by New Zealand Small to Medium-sized Enterprises, Research Letters Inf. Math Sci. Vol.2,pp.63-70

[32]. Robson, C. (2002), "Real World Research": A Resource for social Scientists and Practitioner researcher (2nd edition), oxford, Blackwell.

[33]. Saunders M, Lewis, P and Thornhill, A. (2007),"Research Methods for Business Students," 6th edition, Pearson Education Limited

[34]. Saunders, M, Lewis, P. and Thornhill, A. (2000), Research, methods for Business Students (2nd edition.), Pearson Education Limited.

[35]. Schmiemann, M. (2006), "SMEs and Entrepreneurship in the EU." Industry, Trade and Service European Communities.

[36]. "Small and Medium Business in New Zealand": Report of the Small Business Advisory Group. Characteristics of SMEs.

[37]. http://www.med.govt.nz/templates/MultipageDocumentPage2698.aspx (Assessed on 1st May, 2009).

[38]. Silverman, D. (2006), Interpreting Qualitative Data (3rd edition), SAGE Publication, London.

[39]. Storey, D.J (1994), Understanding the Small Business Sector, Routledge, London

[40]. Storey, D.J, and Thompson J, (1995) “The Financing of New and Small Enterprises in OECD Countries”, OECD, Paris.

[41]. Tonge, J. (2001), A Review of Small Business Literature, Part 1: Defining the Small Business, Centre for Corporate and Public Affairs Manchester Metropolitan University Business School. Manchester, UK.

[42]. The Venture Capital Fund http://www.activityventure.com/ (accessed on 3/11/09)

[43]. UN/ECE Secretariat (1997), "SMEs-Their Role in Foreign Trade." A Paper Presented in BSEC Workshop held on 13-14 November in Kyiv (Ukraine). http://www.unece.org/indust/sme/foreignt.htm (21st April, 2008).

[44]. United Republic of Tanzania, Ministry of Industry and Trade (2002), Small and Medium Enterprises Development Policy

[45]. Vargas, D. M. \& Rangel, R. G. T. (2007)," Development of internal resources and capabilities as sources of differentiation of SME under increased global competition: A field study in Mexico". Technological Forecasting \& Social Change, 74, p90-99

[46]. Wasilczuk J. (2000), "Advantageous Competence of Owner/Managers to Grow the Firm in Poland: Empirical Evidence" Journal of Small Business Management, Vol. 38, No.2, pp.88-90.

[47]. Yin R.K. (2003), Case Study Research, Design and Methods (3rd Edition.), Thousand Oaks, Sage Publication Corporation, California Zikmund W. G. (2000), Business Research Methods 6tAuthor Profile 